HoST - Journal of History of Science and Technology

Vol. 14, no. 1, June 2020, pp. 32-51

$10.2478 /$ host-2020-0003

SPECIAL ISSUE

STANDARDS: TAMING KNOWLEDGE?

\title{
Gauss and the Mathematical Background to Standardisation
}

\author{
José Ferreirós \\ IMUS and Departamento de Filosofía y Lógica, Universidad de Sevilla \\ josef@us.es
}

Abstract: Our aim is to explore the links between standardisation, the quantifying spirit, and the discipline mathematics. To do so, we consider the work of Gauss, renowned as a pure mathematician, but professionally an astronomer, and one heavily engaged with all kinds of measuring and precision initiatives. He contributed to the mathematical correction of data with the method of least squares; to observations of high precision in his geodetic work; to the introduction of absolute measures in his collaborations with Weber on terrestrial magnetism; and to the rationalisation of weights and measures in the state of Hannover. Ultimately, the question is to what extent such precision and standardisation activities may have been rooted in the mathematical way of thinking. Mathematics in our tradition has had a strong contemplative bias (theory, theorein in Greek means to contemplate), but it's a fact that mathematics has always had a non-eliminable technical side.

Keywords: Mathematics as art; technique; quantification; precision measurement; absolute measures 
... die Würde der Wissenschaft erfordert doch, daß man die Natur dieser Ungleichheit klar begreife.

(... but the dignity of science requires that we understand clearly the nature of this inequality). ${ }^{1}$

The nineteenth century was a golden age of (precision, industrial) standardisation. Links between the first and second industrial revolutions and this movement are obvious, but one can raise the question whether there are also links, more generally, with the spirit of the evolving scientific movement. Years ago, Heilbron and other historians argued that there is a "quantifying spirit" characteristic of the late eighteenth century, quite well represented in empirical research of the era (experimental physics, statistics, and so on). ${ }^{2}$ In this paper, I propose to explore the links between standardisation, the quantifying spirit, and the discipline mathematics. To do so, we shall start with a review of some aspects of the work of the princeps mathematicorum Carl F. Gauss (1777-1855). Beyond his legendary name as a pure mathematician, professionally Gauss was an astronomer and he became heavily engaged with all kinds of measuring and precision initiatives: the mathematical correction of data with the method of least squares; observations of high precision ("astronomical precision") in his geodetic work; the introduction of absolute measures in his collaborations with Weber concerning terrestrial magnetism; the rationalisation of weights and measures in the state of Hannover. Indeed he pioneered the CGS system, or to be precise, its forerunner the system millimetre-milligram-second, in 1832.

Rather than concentrate on the technical details of all these initiatives, we shall consider the question to what extent they may have been rooted in the mathematical way of thinking. As we shall see, this can well be argued for the reduction of scientific units to the basic ones of millimetre-milligram-second, the basic idea behind the concept of a scientific system of units. Mathematics in our tradition has had a strong theoretical component, or contemplative bias (theorein in Greek means to contemplate), but mathematics has always had a non-eliminable technical side. As Spanish mathematician Luis Santaló said, it is both "a philosophy" and "a technology,"3 our case study bearing witness to the latter aspect.

Following this line of thought, we shall end up suggesting some senses in which key mathematical proposals of the nineteenth and early twentieth century can be regarded as

\footnotetext{
${ }^{1}$ Gauss to Olbers, March 1827. C. F. Gauss - H. W. M. Olbers: Briefwechsel (Berlin: J. Springer, 1909), 471.

2 Tore Frängsmyr, John L. Heilbron, and Robin E. Rider, eds., The Quantifying Spirit in the 18th Century (Berkeley: University of California Press, 1990).

${ }^{3}$ Luis A. Santaló, La matemática: una filosofía y una técnica (Barcelona: Ariel, 1994).
} 
forms of standardisation within mathematics itself.

\section{Gauss and Standardisation: an Overview}

In 1828 Carl F. Gauss, Director of the Astronomical Observatory at Göttingen, was nominated a member, and chairman, of the Hanoverian Commission for the regulation of weights and measures. Other members of the commission were the senior councillor on Revenue, the senior councillor on Customs, a privy cabinet councillor, as well as the captain of artillery Müller. So, the Commission included a scientist, state functionaries, and a military officer. ${ }^{4} \mathrm{~A}$ typical configuration for the time. It became active from 1836 and Gauss was heavily involved until 1839 (together with his mechanic Moritz Meyerstein), conducting the necessarily tedious precision weighing of the weight standards, including details about the specific weight of the material, etc. ${ }^{5}$ With pauses and diminishing engagement, Gauss' metrological work extended almost until his death in the middle of the 1850s.

This was not his first engagement in such questions. Particularly noteworthy is the truly big work he did on geodesy and cartography of the Kingdom of Hannover from 1820 to 1825. Plans started in 1818, the cartography of Hannover being coordinated with that of neighbouring countries, particularly Denmark, where Schumacher was triangulating Holstein (it was H. C. Schumacher, astronomer at Altona and editor of Astronomische Nachrichten, who proposed the project to his correspondent Gauss). But we should also point to Gauss' long-standing interest in precision instruments, like the heliotrope he invented for his cartography of the Kingdom of Hannover. His careful attention to such matters started at least from the time when he purchased new instruments for the Göttingen Observatory (this led to an interesting trip to Bavaria in 1816, where he met J. Fraunhofer and instrument-maker G. von Reichenbach). ${ }^{6}$

Quite naturally, that was accompanied by great interest in the design of experiments, and in extremely careful precision measurement. An example of this can be taken, again, from his geodetic researches. In this context, Gauss posed himself the challenge of measuring his basic triangles with greater accuracy than anybody before, and thus he made high-precision

\footnotetext{
${ }^{4}$ See Klaus Hentschel, "Gauss, Meyerstein and Hanoverian Metrology," Annals of Science 64, no.1 (January 2007): 41-75.

5 There were connections between Hanoverian and British weights and measures, as William IV was not only King of the United Kingdom but also King of Hanover, Duke of Brunswick and Lüneburg. From 1836, after London issued a new law, 23 English feet equalled 24 Hanoverian feet, reasonable but tedious in practice. Hentschel, "Gauss, Meyerstein and Hanoverian Metrology," 41-42.

${ }^{6}$ For details concerning Gauss' life one can see e.g. Guy Waldo Dunnington, Carl Friedrich Gauss: Titan of Science, revised edition by Jeremy Gray (Washington: Mathematical Association of America, 2004), Hans Wussing, Carl Friedrich Gauss (Leipzig: B. G. Teubner, 1974), or Walter K. Bühler, Gauss - Eine biographische Studie (Berlin: Springer Verlag, 1987).
} 
measurements of the Big Triangle between the heights of Brocken, Hoher Hagen and Inselsberg (with sides of $69 \mathrm{~km}, 84 \mathrm{~km}$ and $106 \mathrm{~km}$ ). The precision he was able to attain was only surpassed in the mid-twentieth century, and the measuring of that Big Triangle also allowed him to make an empirical test of the validity of Euclidean geometry. ${ }^{7}$ Another example from the same set of researches was the measurement of the Breitenunterschied (difference in latitude) between the astronomical observatories in Göttingen and Altona (this was important for the connection between the triangulation of Hannover and that of Denmark, led by Schumacher at Altona).

Gauss was a master of combining his more practical work of precision measurement and observation with theoretical considerations. Interestingly, there seems to be here some resemblance between the solidity of Gauss as a scientist, and his personal appearance (at least as perceived by people like Thomas A. Hirst and Richard Dedekind). "Personally he is a venerable, fine old fellow, with a contented manly expression" wrote Hirst on 12 Aug 1852. "There is an extraordinary aspect of power about him and his every word: without effort he suggests to everyone the presence of a manly might."

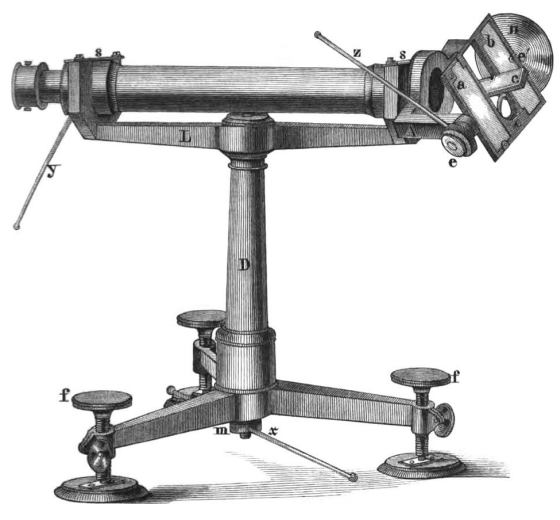

Figure 1 - The heliotrope in 1821.

Karl M. von Bauernfeind, Elemente der Vermessungskunde (München: J.G. Cotta, 1862)

\footnotetext{
${ }^{7}$ See Erhard Scholz, “C. F. Gauss’ Präzisionsmessungen terrestrischer Dreiecke und seine Uberlegungen zur empirischen Fundierung der Geometrie in den 1820er Jahren," in Form, Zahl, Ordnung. Studien zur Wissenschaftsgeschichte, eds. Rudolf Seising, Menso Folkerts, and Ulf Hashagen, 355-380 (Stuttgart: Steiner, 2004).

${ }^{8}$ The Hirst notebooks are preserved in the library of the Royal Institution (see http://www-history.mcs. st-and.ac.uk/HistTopics/Hirst_comments.html, accessed May 13, 2020). Dedekind wrote about the "sight of his stately, awe-inspiring appearance" and regarded it as an "unforgettable" experience, when Gauss while teaching decided to emphasize a certain word or a viewpoint, raising his head and fixing his "penetrating blue eyes" on one of the students. See Richard Dedekind, "Gauß in seiner Vorlesung über die Methode der kleinsten Quadrate," in Gesammelte mathematische Werke, vol. 2, 293-306 (Braunschweig: Vieweg, 1931), originally published in Festschrift zur Feier des hundertfünfzigjährigen Bestehens der Königlichen Akademie der Wissenschaften zu Göttingen (1901).
} 
It may seem a waste of time and energy that such an intellect as Gauss devoted so many hours to tiresome calculations and measurements for the cartography of Hannover, but the fact is that he turned this practical work into the motivation for his study of the differential geometry of surfaces. Published in 1828, Gauss' Disquisitiones generales circa superficies curvas opened a new era for differential geometry and led to higher things in the hands of Riemann, Beltrami, and others. It's in reference to that theoretical work, and the way it sheds light on some problems of the basic methods of triangulation in geodesy, that he wrote the sentence quoted at the start - "but the dignity of science requires that we understand clearly the nature of this inequality." The "dignity of science" is a phrase that reminds one of C. G. J. Jacobi and the role of Neohumanism in the self-conception of many scientists in the Germanic territories around that time. ${ }^{9}$

In a related vein, one has to emphasize the great geophysical research project started by Alexander von Humboldt with the Magnetische Verein, which worked towards establishing a truly international network of magnetic stations, in order to obtain data on the temporal and spatial variations of terrestrial magnetism. ${ }^{10}$ In this context, Carl Gauss and his colleague the physicist Wilhelm Weber not only modified and perfected the protocols for data extraction, while turning Göttingen into the centre of the Magnetic Union of international observatories; Gauss also found an occasion here to introduce absolute and independent units of measure. This was a matter of great concern to him, one in which his wide and deep vision of scientific study could be realised, so as to find a bridge between the orientation towards praxis typical of an experimental scientist, and the turn to theoria characteristic of a theoretical scientist - quite especially, of a mathematician in his time. Remember Santaló: a technology and a philosophy.

The presence of a great experimental physicist who also had a mind for mathematical work, W. Weber, in Göttingen since 1831, offered Gauss excellent chances for expanding his field of

\footnotetext{
9 See Eberhard Knobloch, Herbert Pieper, and Helmut Pulte, “.... das Wesen der reinen Mathematik verherrlichen' Reine Mathernatik und mathematische Naturphilosophie bei C.G.J. Jacobi," Mathematische Semesterberichte 42 (1995): 99-137; José Ferreirós, "Ho theos arithmetidsei. The Rise of Arithmetic as Pure Mathematics with Gauss," in The Shaping of Arithmetic after C.F. Gauss's Disquisitiones Arithmeticae, eds. Catherine Goldstein, Norbert Schappacher, Joachim Schwermer, 234-268 (Berlin, Springer, 2006).

${ }^{10}$ There were fifty observatories, of which thirty-five in Europe, six in Asia, two in Africa, three in North America and four in the Southern Seas. On the Magnetic Union, see Christa Jungnickel and Russell McCormmach, Intellectual Mastery of Nature, vol. 1 (Chicago: University of Chicago Press, 1986); Wilfried Schröder and Karl Heinrich Wiederkehr, "Geomagnetic research in the 19th century: a case study of the German contribution," Acta Geodaetica et Geophysica Hungarica 37, no. 4 (2002): 445-466. See also Andre Koch Torres Assis, Karin Reich, and Karl Heinrich Wiederkehr, "On the Electromagnetic and Electrostatic Units of Current and the Meaning of the Absolute System of Units - For the 200th anniversary of Wilhelm Weber's birth," Sudhoffs Archiv 88, no. 1 (2004): 10-31; Karl Heinrich Wiederkehr, "Wilhelm Weber und die Entwicklung in der Geomagnetik und Elektrodynamik," GaussGesellschaft Göttingen Mitteilungen 29(1992): 63-72.
} 
interest to magnetism. In a letter to Humboldt, who fancied that he had himself been the main source of his interest in the matter, Gauss emphasizes the role Weber played in connection with experimental issues and practical arrangements, engineering questions included:

I cannot really say that the insignificant experiments which I conducted five years ago when I stayed with you prompted me to occupy myself with magnetism. My interest goes back for more than forty years - it is as old as my interest in the exact sciences altogether, but I have to confess that I devote my attention to a subject only if I have the means to penetrate deeply. This was not the case previously. The amiable relation which I have with our good Weber, his enormous kindness in putting the physics laboratory completely at my disposal and assisting me with all his wealth of practical ideas, made my first steps possible. ${ }^{11}$

This became the context for renewed investigations into theoretical issues, particularly potential theory, a quite central nineteenth-century mathematical development that started in the theory of gravitation but was recognized to solve a wide range of problems in mathematical physics, in particular electrostatics and magnetism. ${ }^{12}$ Gauss and others considered potentials not only for problems concerning the mutual attraction of positive masses, but also for problems with "masses" of arbitrary sign, i.e. charges. But, as mentioned before, this context was also the central motivation for Gauss' great concern for a redefinition of the whole system of scientific measurement units, leading to a standard system of absolute and independent measures; in 1832 he proposed to start from the basis system millimetre-milligram-second.

We shall see that one can establish close connections between the basic orientation of mathematical research, and the spirit behind Gauss' proposal of a standard system of scientific units. It is worth noticing that his interest in absolute units extended even to apparently disconnected areas, in particular to his (unpublished but widely cited) research on nonEuclidean geometry. It's well known that, after 1816 at least, Gauss was convinced of the consistency of non-Euclidean geometry of the Lobachevsky-Bolyai type, and in his related letters to colleagues he remarks that one of the pros of such a system (in contrast to traditional Euclidean geometry) is the existence of an absolute unit of length. "It would even be desirable if Euclidean geometry were not true, since we would then have a common measure a priori" ${ }^{14}$ : the internal configuration of line properties in non-Euclidean geometry leads to the definition of an absolute length, and length is Nature's most important dimension.

\footnotetext{
${ }^{11}$ Gauss to Humboldt, 1833. Bühler, Gauss, translated in p. 128.

12 See e.g. Jeremy Gray, The Real and the Complex: A History of Analysis in the 19th Century (New York: Springer Verlag, 2015), chap. 13; Andrei N. Kolmogorov and Adolf-Andrei P. Yushkevich, eds., Mathematics of the 19th Century: Geometry, Analytic Function Theory (Basel: Birkhäuser, 1996).

13 See Bühler, Gauss, 100, 101.

${ }^{14}$ Letter to Gerling, April 1816. In Gauss's Werke, vol. 8 (Göttingen: Akademie der Wissenschaften, 1900), 168-169.
} 


\section{Interlude: Precision Measurement in the Nineteenth-Century Germanies}

Let us consider the broader cultural context of the events and results we have been reviewing. Two decades ago, Kathryn Olesko wrote that "No other nation in the world has been identified with precision measurement as much as Germany has." 15 This relates very particularly to developments in the nineteenth century, when Germany experienced its quick process of industrialisation, during which precision industries (like Siemens for telegraphy and electricity or Zeiss for precision mechanics-optics, to name just two) became a trademark of Germany. In the last third of the century, the Physikalisch-Technisches Reichsanstalt (Imperial PhysicoTechnical Institution, inaugurated 1887) had become a true symbol of the power and authority of the II Reich.

Olesko underscores the transformation in the nature of measurement along the nineteenth century, which involved many different facts or aspects: epistemological, material, legal, moral, technical and cultural. ${ }^{16}$ One can thus speak of a whole culture of precision that became characteristic of the new industrialised Nation-States. In the particular case of Germany that she studies, Olesko calls attention to two faces of the issue. First, the great importance that the probability calculus attained in the Germanies, in the context of verification and certainty of exact measurements; second, the transfer of values previously linked with weights and measures (practical standards for commerce) to the new experimental practices. Such defining values include honesty or trust (fiabilidad, Zuverlässigkeit or Verlässlichkeit), veracity and integrity - ideas and values that were scarcely visible, she argues, in refined measurement as practiced during the eighteenth century, but which became fundamentally important for the exact sensibility of the early nineteenth. ${ }^{17}$

In the process, experimentation gained exactness if all kinds of ways, in the design of experiment, the protocols, the written presentation of results, and of course the numerical results. ${ }^{18}$ The determination of exactness involved consideration of quantitative but also qualitative issues, material and technical questions as much as moral and psychological ones; it concerned so much the researcher himself as the experimental procedures and the measurements. To insist on a well-known idea, the rise of the discipline physics was simultaneous with the disciplining of the community of physicists, inseparable from it.

\footnotetext{
15 See Kathryn M. Olesko, "The Meaning of Precision: The Exact Sensibility in Early NineteenthCentury Germany," in The Values of Precision, ed. M. Norton Wise, 103-134 (Princeton Univ. Press, 1995).

${ }^{16}$ Ibid., 103-105.

17 Ibid., 104.

18 Ibid., 105.
} 
A careful trade-off was established between the search for exactness and the recognition of error, and this became one of the most characteristic features of nineteenth century science. Prevision, the probability of truth, are obtained as the reversal of a theory of error - the level of precision is measured by estimating the error. ${ }^{19}$ The ad hoc methods of the eighteenth century, its "rhetoric of precision" based on appeals to "mathematical exactitude," ${ }^{20}$ were replaced by the new standardized methods. And one central example of such methods is precisely the method of least squares that was introduced by Legendre and Gauss, independently.

We shall thus consider a different strand of Gauss' work which can be linked with the topic of standardisation, the mathematical analysis of data, the theory of errors. With these new methods, they managed to obtain a great reduction and harmonisation of the results of observation, which in relevant cases allowed scientists to narrow significantly the gap between prediction and observation. Gauss regarded this as proof of the mathematical character of Nature - indeed, one of the most direct ways of proving that 'Galilean' fundamental principle. "Thou, Nature, art my goddess - to thy law my services are bound" ${ }^{21}$ was one of Gauss' favourite phrases.

\section{The Production of Mathematically Standardised Data}

It's well known that Gauss became famous very early in his career, in 1801, with two quite significant contributions: one in pure mathematics, his great and influential treatise on number theory, Disquisitiones arithmeticae; the other in mathematical astronomy, his calculation of the orbit of the first dwarf planet, Ceres, from very scanty data of observation. Laplace is said to have commented that the Duke of Brunswick had "discovered more in his country than a planet: a super-terrestrial spirit in a human body." 22 Gauss had recently completed his doctoral degree and, still 24 and now interested in mathematical astronomy, was living in his native Brunswick, supported by an annual stipend from the Duke. The astronomical feat may have been achieved by employing, among others, the method of least squares, a most significant innovation in the treatment of data; it's not totally clear that he used the method for Ceres, but there is evidence that Gauss was in possession of Least Squares by 1799.

\footnotetext{
${ }^{19}$ Ibid., 106.

${ }^{20}$ Sven Widmalm, "Accuracy, rhetoric, and technology: The Paris-Greenwich triangulation, 1784-88," in Frängsmyr et al., The Quantifying Spirit, 179-206.

${ }^{21}$ William Shakespeare, King Lear (Hertfordshire: Wordsworth Classics, 1994), act 1, scene 2.

22 See Dunnington, Gauss: Titan of Science, 44 and chap. 5. Further sources and references in: https:// www.cs.xu.edu/math/Sources/Gauss/Gauss.html (accessed April 11, 2020). For the new mathematical methods employed by Gauss to determine the orbit of Ceres from very few orbital elements, and without the position of the perihelium, see Donald Teets and Karen Whitehead, "The Discovery of Ceres: How Gauss Became Famous,” Mathematics Magazine 72, no. 2 (Apr. 1999): 83-93.
} 
The theory of error supplied by this new method was nothing other than a procedure for the standardisation of data, and it gave the German-speaking community of astronomers and physicists one of their identifying traits. The goal was to correct or reduce errors, to quantify the uncertain cancelling out mistakes, and thus to standardise data. The method of least squares teaches that the best fitting curve for a set of (imprecise) observations or measurements is the one that minimises the sum of the squares of deviations. When he first published his own elaboration of the idea in the book Theoria motus corporum covelestium in sectionibus conicis solem ambientium (1809), Gauss presented it as "the principle that the sum of the squares of the differences between the observed and the computed quantities must be a minimum." 23 The method was published for the first time by Legendre in 1805, with great impact on the community of astronomers, but Gauss subsequently claimed that he had known and used it ten years earlier. ${ }^{24}$

Gauss distinguished two kinds of errors in measurements, the accidental or irregular errors which inevitably occur due to imprecisions, and the constant or regular errors due to the instrument or the observer himself (say, because of eyesight problems). Constant errors have to be resolved with better instruments, but also with careful study of their use, and role of the observer in it, finding out about biases in the given situation. This was typical of the more protocolised practices of nineteenth-century science. On the other hand, the method of least squares is an application of probability theory, meant to smooth out the irregular, accidental errors. Gauss would later present the key ideas in many other publications and lectures, underscoring that to make the uncertainty of the results as small as possible, is "undoubtedly one of the most important tasks in the application of mathematics to the natural sciences." ${ }^{25}$ Gauss would make constant use of the method in geodesy, in astronomy, and so on.

As Bessel said, the calculus of probabilities "teaches how we should determine the quality of observations from their differences." 26 Nevertheless, it is a fact that the method was slow in becoming well established, outside the domain of astronomy and geodesy; in the context of experimental physics, it was mostly from 1830 that it was discussed and employed. During the 1830 s and 40 s there appeared several influential uses in chemistry, physics, and even in mineralogy from the hand of F. Neumann, and physiology due to Helmholtz. Thus there

${ }^{23}$ Gauss, “Theoria motus," in Werke, vol. 7, sec. 186 (Göttingen: Akademie der Wissenschaften, 1906), 253.

24 This gave rise to a famous priority dispute, see e.g. Stephen M. Stigler, "Gauss and the Invention of Least Squares," Annals of Statistics 9, no. 3 (1981): 465-474. Apparently the first glimpses of such a method, and clear statement of the goals, was due to Lambert.

25 Carl F. Gauss, "Theoria combinationis observationum erroribus minimis obnoxiae," Commentationes societatis regiae scientarium Gottingensis recentiores, 5 (1823); reprinted in his Werke, vol. 4, 1-26 (Göttingen: Akademie der Wissenschaften, 1873).

${ }^{26}$ Cited in Olesko, "The Meaning of Precision," 108. 
emerged a theory of error, superseding the previous intuitive ideas.

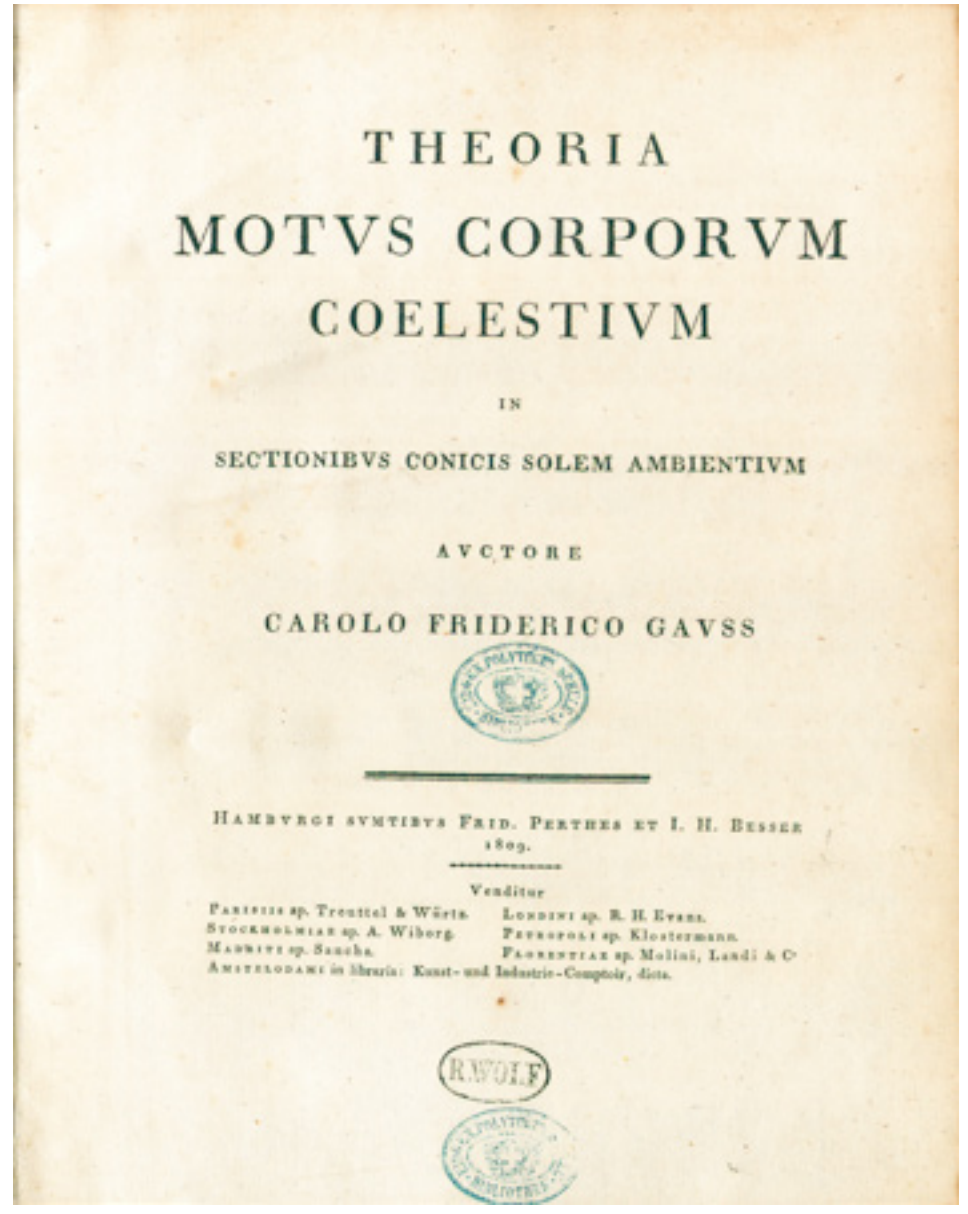

Figure 2 - Title page of the 1809 Theoria motus

Gauss, Theoria motus corporum coelestium in sectionibus conicis solem ambientium (Hamburg: F. Perthes \& I. H. Besser, 1809)

Let me add two more comments. Concerning the definition of the sum of the squares of the distances as the key quantity that must be minimized, this is a conventional assumption and not the only possible choice. Gauss recognized the objection that there is here "a principle" that is not necessary, but to some extent arbitrary - in any event, the value must be measured by a function of the single errors that is always positive. ${ }^{27}$ He mentioned Laplace's "ratio" (employing the absolute value of the distances) and compared it with his own. Gauss viewed them both as tractable, "quaestio est neque per se clara, neque demonstrationibus mathematicis decidenda, se libero tantum arbitrio remittenda" (the question is neither clear by itself, nor to

27 See the quote in Ian Hacking, Logic of Statistical Inference (Cambridge: Cambridge University Press, 1965), 161. 
be resolved by mathematical proof, but must be decided freely); but his principle recommends itself by its consequences, by "their wonderful simplicity and generality." ${ }^{28}$ Later Andrei A. Markov would establish general results proving the optimality of Gauss' least square criterion (Gauss-Markov theorem).

Least squares was one of Gauss' key methods in the practice of exact science. It was also key in his vision of how nature and mathematics fit: the very success of this mathematical method of data analysis, as shown e.g. in the case of Ceres, was clear proof in his eyes of the mathematical character of natural phenomena. That proof he regarded as equally good, or even better, than any other - say, by appeal to the extreme precision of Newton's Law of Gravitation. Thus, even when we cannot determine the mathematics of Nature, God is always doing arithmetic (ho theos arithmetidsei). Interestingly, in a paper on the laws of mechanics, introducing his principle of the least constraint (Princip des kleinsten Zwanges), Gauss writes as follows:

It is very noteworthy that the free movements, if they do not occur according to necessary conditions, are modified by Nature in the same way that a calculating mathematician, using the method of least squares, smooths out experiences that are linked to one another as quantities interrelated by a necessary dependence. This analogy could be developed even further... ${ }^{29}$

\section{Standardising Scientific Units}

Very soon after his engagement with Humboldt's great project of Geo-Magnetism, Gauss displayed a number of theoretical and practical initiatives that would have great repercussion. As we have seen, Weber became professor at Göttingen in 1831 (until 1837 when a famous political issue affected his career), and immediately afterwards Gauss became engaged in experimental issues and practical arrangements, engineering questions included, as well as theoretical considerations. The project led immediately to the need for common standards in measuring techniques - reliability, accuracy, comparability of data. The protocol for measurements taken at all stations of the Magnetic Union was actually set by Gauss and Weber, deviating from Humboldt's more impractical ideas. It is in this context that we have to place his great concern for absolute and independent units of measure. Notice that it all had to do

\footnotetext{
${ }^{28}$ Quotes from Gauss, “Theoria combinationis observationum ...,". See the bilingual edition Theory of the Combination of Observations Least Subject to Errors, trans. Gilbert W. Stewart, Classics in Applied Mathematics (Philadelphia: Society for Industrial and Applied Mathematics, 1995), 10-11.

29 Gauss, "Ueber ein allgemeines Grundgesetz der Mechanik," Journal für reine und angewandte Mathematik 4 (1829): 232-235, on 235. According to this principle, "the motion of a system of material points, constrained in an arbitrary manner, and subjected to arbitrary forces at any moment of time, takes place in a manner which is as similar as possible to the motion that would be performed by these points if they were free, i.e. with least-possible forcing — the measure of forcing during the time $d t$ being defined as the sum of the products of the mass of each point and the square of the distance of the point from the position which it would occupy if it were free." Ibid., 233.
} 
with the implementation of astronomical practices (ways of doing, ideals, precision standards, etc.) in the rest of physics.

The project, started in 1832, progressed quickly. In 1833 a new magnetic observatory was set in place at Göttingen. ${ }^{30}$ The Magnetischer Verein (Magnetic Union) would have Göttingen as its centre, and its journal, Resultate aus den Beobachtungen (Results from the Observations of the Magnetic Union) was edited in six volumes from 1836 to 1841 . Measurements were taken in the course of those six years, during twenty-eight chosen days (Termintagen), with the collaborators measuring every five minutes for twenty-four hours in a row. Around fifty observatories were engaged, as we have mentioned.

The results were sent to Göttingen and analysed by Gauss and Weber according to theoretical principles. In 1839 Gauss published his paper Allgemeine Theorie, "General theory of terrestrial magnetism," leading to a theoretical characterization of the magnetic field, based on the mathematics of potential theory. In 1840, the monumental Atlas des Erdmagnetismus was edited, under the direction of Gauss and Weber with the help of C. W. Benjamin Goldschmidt. In the maps that were published as the Atlas, accompanying the work published in Resultate, there were lines uniting points of the same declination, the same inclination, and the same magnetic intensity. These publications were a landmark of nineteenth-century science. One of the greatest surprises was the discovery of the changes of intensity of the magnetic force in time.

Already in 1832, Gauss proposed the possibility of making magnetic measurements in terms of mechanical units of the earth's magnetic force as "absolute measure." ${ }^{11}$ The idea of defining an absolute measure of magnetic force came down to reducing the units of magnetic force to basic mechanical units and forces. Thus, the "unit magnetic fluid" is a force such that it repels another unit magnetic fluid at distance 1 with intensity 1 . For this to be feasible, one has to choose a basic system of mechanical units, and Gauss proposed the system milligrammillimetre-second. It is well known that a half-century later, in 1889, the meter-kilogramsecond (MKS) system would be chosen in the course of an International Congress in Paris (even later superseded by the centimetre, gram and mean solar second (CGS) system); but in any event it was always a system based on units for the basic quantities mass, length, time, and derived units for other essential quantities. ${ }^{32}$

\footnotetext{
${ }^{30}$ See Bühler, Gauss, 128. It is very well known that this led to the invention of a magnetometer and the establishment of a telegraphic connection between the Observatory and the Physics Institute.

${ }^{31}$ Carl F. Gauss, "Intensitas vis magneticae terrestris ad mensuram absolutam revocata," in Werke, vol. 5, 293-304 (Göttingen: Akademie der Wissenschaften, 1832).

32 For instance, in the MKS system force is measured by the derived unit, the Newton, which corresponds to $1 \mathrm{~kg} \cdot \mathrm{m} \cdot \mathrm{s}^{-2}$.
} 
It was Gauss' 1832 paper that established the need for such definitions, which doesn't seem to have been obvious for his contemporaries. And his basic outline of the system, which reinforced the French principles of the decimal system, was the basis for later proposals in Germany, England and France. Thus, W. Weber published his "Electrodynamic Measures" (1851) proposing absolute units for electric currents, which provided a complete set of "absolute units." ${ }^{33}$ In 1861, the British Association for Advancement of Science (a body that included W. Thomson, J.C. Maxwell and J.P. Joule) introduced the concept of the CGS system of units. Even though in 1889 the resolution would be in favour of the MKS system, in the twentieth century there was a return to the CGS. Minor matters of detail, where the essential question is the idea of such a system itself, based on units for length, mass and time.

\section{The Mathematical Background to Standardisation}

Gauss' most original contribution in magnetism, his famous definition of an absolute measure of magnetic force, can be understood as a clear example of the mathematical way of thinking at work. The guiding idea is simply to provide a reduction of the basic units of magnetism to those of mechanics, at a time when mechanics was regarded as the basis of all physics. Such a reduction is just the way of working typical of axiomatics - consider the reduction of theorem to axioms by means of proof, and more to the point the reduction of derived concepts to primitive ones (by means of definition). In geometry, a triangle is easily defined in terms of more fundamental concepts of segment, point, plane; in arithmetic, the concept of prime number is reduced to the idea of divisibility, which in turn is reduced to the primitive concept of product; in set theory, the notion of inclusion is defined in terms of the primitive notion $\varepsilon$ of elementhood. Similarly, Gauss considered that the fundamental mechanical quantities (length, mass, time) could be employed as the basis for sound definitions of other derived units, based on natural laws or - at least - on seemingly universal conventions.

Thus one can claim that Gauss' proposal of absolute measurements and standard scientific units is a product of the axiomatic way of thinking applied to physical disciplines. ${ }^{34}$ This fits quite well with the role Gauss played in mathematics itself, as a strong advocate of the return to Ancient standards of rigor and proof. ${ }^{35}$ Although this is not too often mentioned, already his early works (the 1799 dissertation on the fundamental theorem of algebra, the 1801 Disquisitiones

\footnotetext{
33 Wilhelm Weber, "Elektrodynamische Massbestimmungen," in Wilh. Weber's Werke, vol. 4 (Berlin: Springer, 1894).

${ }^{34}$ I do not claim that mathematics was the only relevant background. The experimental way of thinking is seen at work, contrarywise, when the measure of the basic units of mechanics is established in reference to noteworthy natural phenomena - the second as a fraction of the (mean solar) day, the metre as a fraction of a carefully measured meridian, the gram as the weight of a cubic centimetre of water.

35 See Ferreirós, "Ho theos arithmetidsei. The Rise of Arithmetic as Pure Mathematics with Gauss."
} 
arithmeticae) were marked by the goal of establishing more strict standards of rigor and the ideal of a systematically organized theory. His friend and biographer, S. von Waltershausen, explained that he understood science to be "that rigorous logical edifice, closed in itself, whose foundations rest on some truths generally acknowledged by the human mind," truths which "open for us an immense field of most intricate researches, linked to one another by an iron chain of thoughts." ${ }^{36}$ And it would have been for this reason that he regarded pure arithmetic as the queen of the mathematical disciplines. A similar idea was emphasized by a deeper connoisseur of Gauss' work, the important English mathematician H. J. S. Smith:

If we except the great name of Newton it is probable that no mathematicians of any age or country have ever surpassed Gauss in the combination of an abundant fertility of invention with an absolute rigorousness in demonstration, which the ancient Greeks themselves might have envied. It may seem paradoxical, but it is probably nevertheless true that it is precisely the efforts after logical perfection of form which has rendered the writings of Gauss open to the charge of obscurity and unnecessary difficulty.... It is not the least of Gauss' claims to the admiration of mathematicians, that, while fully penetrated with a sense of the vastness of the science, he exacted the utmost rigorousness in every part of it, never passed over a difficulty, as if it did not exist, and never accepted a theorem as true beyond the limits within which it could actually be demonstrated. ${ }^{37}$

Another clear instance of such ways of thinking was Gauss' lifelong interest in the question of the axiom of parallels, and the possibility of non-Euclidean geometry; or his lifelong interest in "the metaphysics of the complex numbers," which is to say, on the search for a rigorous definition and introduction of those numbers (by the "metaphysics of mathematics" he, like other authors around 1800, meant philosophical foundations).

A glimpse of his admiration for the Ancients and their way of practicing mathematics can be found in the following letter to Schumacher (Sept 1, 1850):

It is the character of the mathematics of modern times (in contrast to Antiquity) that with our symbolic language and terminology we possess a lever, by which the most complex arguments are reduced to a certain mechanism. Thereby the science has won infinitely in richness, but in beauty and solidity how the trade is usually practiced, it has lost just as much. How frequently that lever is applied in a merely mechanical way, although the authorization to do so implies in most cases certain tacit assumptions. It is my request that, by every use of the calculus, by any application of concepts, one should always remain aware of the original conditions, and never consider the products of the mechanism as a property

${ }^{36}$ Sartorius Von Waltershausen, Gauss zum Gedächtniss (Leipzig: S. Hirzel, 1856), 97.

${ }^{37}$ Henry John Stephen Smith, "Presidential Address," Proceedings of the London Mathematical Society 8 (1876); reprinted in The Collected Mathematical Papers of H. J. S. Smith, ed. James Whitbread Lee Glaisher, vol. 2, 681-690 (Oxford: Clarendon, 1894). 
beyond that explicit authorization. ${ }^{38}$

All this is not to deny that the axiomatic method still had a long way to go, before it found its highly influential "modern" formulation in the work of Hilbert. But one can clearly see Gauss as one of the figures starting the movement.

\section{Mathematics and Standardisation, Again}

It is worthwhile to inquire a bit more into the reasons for this harmonic relation between mathematics and standardisation. We have seen that maths influenced the precision and standardisation movement of the nineteenth century, through figures such as Gauss, Bessel, and other astronomers - more generally, through the impact of the astronomical vision of Nature in physics and beyond. Can we also, conversely, think that standardisation may have influenced mathematics?

Indeed. Mathematics is in a sense the outcome of standardisation, for already the number concept is a product of methodologies for measuring, and measuring always presupposes a standard (a unit). Ancient measures were based on the standard length of various parts of the human body (this happens e.g. with the Egyptian cubit), just like the second is approximately the duration of a heartbeat. Some much later examples of old measures from my own corner of this world: lengths such as the vara de Burgos $(83.8905 \mathrm{~cm})$, legua (1 legua real was 6.687 $\mathrm{km})$, or volumes like the moyo $(=16$ cántaras i.e. $258.128 \mathrm{~L})$ or the arroba $(=8$ azumbres i.e. $16.133 \mathrm{~L}$ ). By giving their values in modern units, I have already showed the need for rational numbers (fractions) in the process of linking various units, and more generally in measuring. But to emphasize only that side of things would be biased.

In mathematics, there is also the element of idealisation, of celestial precision, for without the "divine" geometry and its quite unreal idealisations (invisible points, one-dimensional lines) the need for irrational numbers would never had arisen. This latter element corresponds to what I have called the presence of "constitutive hypotheses" or idealisations in advanced mathematics. ${ }^{39}$

But there is more to maths and standards. First, it is instructive to realize that mathematicians make frequent use of the word "standard." The reader may have already felt it in paragraphs of the previous section, but if we take a book such as Mac Lane's Mathematics: Form and

\footnotetext{
${ }^{38}$ Gauss to Schumacher, discussing a paper on divergent series, see Gauss, Werke, vol. 10-1 (Göttingen: Akademie der Wissenschaften, 1917), 434-435.

39 See José Ferreirós, Mathematical Knowledge and the Interplay of Practices (Princeton: Princeton University Press, 2016), chap. 6.
} 
Function, ${ }^{40}$ the fact is that it has many, many uses for the word "standard." To wit, here are some that I have noticed and extracted (the quotes are verbatim):

standard algebraic manipulations of addition, subtraction, and multiplication.

standard rules for "change of variables"

the "standard" inner product

the standard axioms for the real numbers

standard formula for the solution of a quadratic equation.

Standard logical connectives, quantifiers...

Three dimensional vector spaces are standard in physics,

the standard isomorphism of such a space to its dual...

And of course one finds references to "standard notations," "standard terminology" or "standard sources in the literature," which however would be common in all sciences.

Now, if we are to ask about the standardisation mentality at work in pure mathematics, probably the most significant instance is formal proof as the "standard of rigor" (Euclidean proof was the older standard, replaced around 1910). This logical standard was first imagined by G. Frege in 1879 as an epistemological safeguard, and then turned into its modern role by Hilbert and his school in the 1920s. It has affected even the practice of mathematical communication, particularly by relegating diagrams and pictures to the role of mere heuristic devices which (however important they may be for the individual mathematician, or in his communication with peers) should not be displayed in printed papers. Mac Lane comments:

Proof in Mathematics is both a means to understand why some result holds and a way to achieve precision. As to precision, we have now stated an absolute standard of rigor: A Mathematical proof is rigorous when it is (or could be) written out in the first order predicate language $L(\mathbb{\nabla})$ as a sequence of inferences from the axioms ZFC, ${ }^{41}$ each inference made according to one of the stated rules [of logical inference, JF]. ... When a proof is in doubt, its repair is usually just a partial approximation of the fully formal version. What is at hand is not the practice of absolute rigor, but a standard of absolute rigor. ${ }^{42}$

Certainly the idea is widespread. The view that axiom system ZFC is the basic "shared standard" was dominant by the mid-twentieth century. Even Soviet mathematicians would agree on this point, as one can see e.g. through the work of Kolmogorov, an extraordinarily influential

\footnotetext{
40 Saunders Mac Lane, Mathematics: Form and Function (New York: Springer Verlag, 1986).

${ }^{41} \mathrm{ZFC}$ refers to the Zermelo-Fraenkel axiom system for set theory, with the axiom of Choice.

42 Mac Lane, Math: Form and Function, 377.
} 
figure, perhaps the best Russian mathematician. Thus in the historical paper 'Newton and contemporary mathematical thought', Kolmogorov contrasts Newton's "rigor" and "modern 'set-theoretic rigor'." 43 The ideal set-theoretic standard is seldom used, but when there are doubts or disagreements it can be employed. ${ }^{44}$

These initiatives of course have their own history. In fact, the histories converge, and if we look for the origins of the set-theoretic axioms (or way of thinking) and the origins of modern rigorous proof, it's natural to trace them back to Gauss. The set-theoretic approach to mathematical theories began to emerge from the arithmetisation movement from about $1850 .{ }^{45}$ Starting already with Gauss and the Berlin professor Martin Ohm (brother of the famous physicist), but increasing with Weierstrass and Dedekind, this was the idea that all of pure mathematics is the science of numbers, it is all Arithmetic (in a generalized sense) ${ }^{46}$ With Ohm, Weierstrass and Dedekind came the thought of reducing different kinds of numbers to the natural numbers, but then in the 1880s the natural number system was in turn reduced to sets. The work of Dedekind and Frege, then of Cantor, and subsequently of Zermelo and others, established that point.

Arithmetisation of analysis was also the context where the new standard of rigor was established. It is a well-known story that Weierstrass and his Berlin school, around 1870, established the new practice of rigor in analysis, the $\varepsilon-\delta$ methodology which finally made it possible to prove in all detail the truths of mathematical analysis. Weierstrass eliminated the infinitesimals in favour of the concept of limit set upon a rigorous theory of real numbers - the latter simplified and perfected by Dedekind and Cantor. But Weierstrass's methods, so goes the story, can be traced back to the work of Cauchy and Bolzano... and Gauss. ${ }^{47}$ In particular, Bolzano's

${ }^{43}$ The text is found in Kolmogorov in Perspective, (Providence: American Mathematical Society/London Mathematical Society, 2000), History of Mathematics, vol. 20, 163 footnote. See also Andrei Kolmogorov, "Mathematics" in Great Soviet Encyclopedia (1954), with a Spanish version published in La Gaceta de la Real Soc. Mat. Española 9, no. 1 (2006): 99-141.

44 I quote Mac Lane again: "The standard foundation for Mathematics intends to build up all Mathematical concepts out of sets" (Math: Form and Function, 362) with the help of "a formal definition of 'proof" (Ibid., 358). A very recent, modernised version of all this comes with automated theorem provers and computerised Proof Checking systems.

45 See, among others, José Ferreirós, Labyrinth of Thought: a history of set theory and its role in modern mathematics (Basel: Birkhäuser, 2007), chap. 1 and passim.

${ }^{46}$ Ferreirós, "Ho theos aritmetidsei. The Rise of Arithmetic as Pure Mathematics with Gauss." This means that the number system reaches all the way up to the real and complex numbers, and that the means of arithmetisation make it possible to develop algebra and analysis. Dedekind attributed to Dirichlet the idea that "every theorem of algebra and higher analysis, no matter how remote, can be expressed as a theorem about natural numbers" and he also wrote: "I demand that arithmetic shall develop out of itself." Richard Dedekind, Gesammelte mathematische Werke, vol. 3 (Braunschweig: Vieweg, 1932), 321 and 338 .

47 See e.g. Hans Niels Jahnke, A History of Analysis (Providence: American Mathematical Society/London Mathematical Society, 2003). 
celebrated paper of 1817, offering a Rein analytischer Beweis (purely analytical proof) of the Intermediate Value Theorem, was seen by Weierstrass as a landmark for his own work - but in turn Bolzano was strongly influenced by Gauss' two proofs (in 1816) of the Fundamental Theorem of algebra. ${ }^{48}$ We cannot go into further details here, but I hope the point has been clearly made.

Finally, Frege came up with his idea of a purely formal proof (with an explicit pre-established symbol system, and explicit pre-determined rules of formal inference) as a way of making fully precise the Weierstrassian standard of rigor. One can explain in detail how the predicate logic (quantification theory) of Frege originates in the careful "arithmetic" style of proof followed by Weierstrass. ${ }^{49}$

One might also present as an example of standardisation the modern algebraic reconstruction of the discipline around the idea of structure, and its subsequent development into a general (set-theoretic) framework for the systematic and uniform presentation of all basic mathematical frameworks, whether in algebra or topology, etc. But it's unnecessary to continue developing the point here. ${ }^{50}$

\section{Conclusions}

Mathematics is a real hybrid of science and art, an interplay of Structures and Algorithms (as Jens Fenstad put it), ${ }^{51}$ of axiomatic abstraction and numerical calculation - or else, as Luis Santaló said, it is both a philosophy and a technique. Some of us tend to emphasize the conceptual, abstract, theoretical, structural side of mathematics, while many writers are inclined to view it almost exclusively from the practical point of view, as the daughter of counting, reckoning and land-measuring (geo-metria). This is the viewpoint of A. Dürer when he entitles his Geometry "the Art of Measurement," the perspective of that ancient sage,

\footnotetext{
48 See Elías Fuentes Guillén, "The Germanic Development of the Pre-Modern Notion of Number" (PhD dissertation, Universidad de Salamanca, 2017), https://numbersandshadows.files.wordpress. com/2018/04/the-germanic-development-of-the-pre-modern-notion-of-number.pdf (accessed April 10, 2020).

49 See José Ferreirós, “The Road to Modern Logic: an interpretation,” The Bulletin of Symbolic Logic 7, no. 4 (2001): 441-484. A very recent, improved version of all this comes with automated theorem provers and computerized Proof Checking systems. An attempt to have both foundation and automated proof simultaneously is being made with HoTT, a foundational system proposed by Vladimir Voevodsky and others.

${ }^{50}$ I thank an anonymous referee for suggesting this. See Leo Corry, Modern Algebra and the rise of mathematical structures (Basel: Birkhäuser, 2004).

51 Jens E. Fenstad, Structures and Algorithms: Mathematics and the Nature of Knowledge (Cham: Springer Verlag, 2018).
} 
Solomon, when he writes: "thou hast ordered all things in measure and number and weight." 52 But this, once again, is not unrelated to Gauss' motto "the God arithmetises."

Gauss was characteristically inclined to place all emphasis on the contemplative side, at least whenever it was a matter of philosophical declarations; he placed emphasis on theoria. The "dignity of science," the "purity" of maths: "All the measurements in the world are not worth one theorem by which the science of eternal truth is genuinely advanced," as he wrote to Bessel (March 1824) ${ }^{53}$ But notice that the context was a defence of the measuring work in triangulation and geodesy against Bessel's deprecation of the loss of time and the scarce value of the results. Philosophical declarations apart, Gauss' life and work was a very sound and balanced compound of theoria and praxis, of general conceptions and concrete measuring work, of the theoretical and experimental practices that define science - and define it through their hybridisation. ${ }^{54}$ It was precisely in the trading zone where both elements encountered, that he advanced new methods for the promotion of precision experiments (spreading the astronomical ways of doing to other parts of physics), for the standardisation of data (least squares), for the establishment of a system of scientific units.

And that solid combination which we find in Gauss is a perfect expression of the dual nature of mathematics and mathematical practices. At this point, let me quote a text due to David Hilbert. In a conference given in 1930 (broadcasted by radio), he read the following words:

The instrument which implements the mediation between theory and practice, between thinking and observing, is mathematics. It builds the connecting bridge and makes it stronger and stronger. Thus it happens that our entire present-day culture, in so far as it rests on intellectual penetration and harnessing of nature, finds its foundations in mathematics. ${ }^{55}$

We have seen that many of Gauss' proposals and initiatives can be seen in retrospect to have promoted such a view on mathematics.

52 What I say of Gauss below is also applicable to Dürer, and may also have been valid of King Solomon. Albrecht Dürer's book is Underweysung der Messung mit dem Zyrkel und Richtscheyt (Nürnberg, 1525); there is a Spanish translation based on J. Peiffer's edition: De la medida (Madrid: Ediciones Akal, 2000).

53 Wussing, Gauss, 62.

54 On this topic see José Ferreirós and Javier Ordóńez, "Hacia una filosofía de la experimentación," Crítica 34, no. 102 (2002): 47-86; and José Ferreirós, "The Dynamics of Experimentation and its Role within a Philosophy of Scientific Practice," in Observation and Experimentation in Science: New methodological perspectives, ed. Wenceslao González, 99-113 (La Coruña: Net·biblos, 2011).

55 Hear the audio in https:/www.maa.org/press/periodicals/convergence/david-hilberts-radio-address. I have combined and modified the translation from that webpage, and http://www.math.ucsd. edu/ $\sim$ williams/motiv/hilbert.html (accessed April 17, 2019). 


\section{Acknowledgements}

Thanks are due to Javier Ordóñez for many talks over the years, to John Heilbron, to my colleagues in APMP, and to Antonio Sánchez and María de Paz for relevant comments.

\section{Competing interests}

The author has declared that no competing interests exist.

\section{Funding}

Research funded by the Spanish State and by projects La Génesis del Conocimiento Matemático: Cognición, Historia, Prácticas (P12-HUM-1216), and La Génesis del Conocimiento Geométrico (FFI2017-84524-P). 